\title{
Entre reformas curriculares e práticas pedagógicas: Ursula Hoadley e a "pedagogia na pobreza"
}

\author{
Cláudia Valentina Assumpção Galian ${ }^{1,2}$ \\ ORCID: 0000-0002-1924-8802 \\ Maurício Braz de Carvalho ${ }^{1}$ \\ ORCID: 0000-0002-1837-5789
}

\section{Resumo}

Nesta entrevista, Ursula Hoadley, docente e pesquisadora da Universidade da Cidade do Cabo, África do Sul, discute algumas das ideias que desenvolve em seu livro Pedagogia na pobreza: lições de vinte anos de reformas curriculares na África do Sul, bem como salienta a potência explicativa da teoria de Basil Bernstein, sua principal referência nesta e em outras investigações no contexto sul-africano. A entrevistada comenta seus principais achados nessa pesquisa, que possibilitou descrever e analisar práticas docentes desenvolvidas por professoras dos anos iniciais do Ensino Fundamental, frente a um movimento de vinte anos de reformas curriculares, no contexto anterior e posterior ao apartheid. Suas reflexões não perdem de vista as especificidades de seu país, mas situam as reformas curriculares estudadas no cenário mais amplo de mudanças em países em desenvolvimento, o que as torna especialmente interessantes para os debates sobre o currículo da educação básica no Brasil.

\section{Palavras-chave}

Reformas curriculares - Práticas docentes - Educação básica.

\section{Between curriculum reforms and pedagogical practices: Ursula Hoadley and the "pedagogy in poverty"}

\section{Abstract}

In this interview, Ursula Hoadley, a professor and researcher at the University of Cape Town, South Africa, discusses some of the ideas present in her book Pedagogy in Poverty: lessons from twenty years of curriculum reform in South Africa. The author highlights the explanatory power of Basil Bernstein's theoretical framework, her main reference both

1- Universidade de São Paulo, São Paulo, SP. Brasil. Contatos: claudiavalentina@usp.br; brazmauricio@usp.br

2- Responsável pelas notas explicativas. 
in this and other investigations in the South-African context. The interviewee comments on her main findings in this research, which allowed her to describe and analyze teaching practices developed in the primary years of Elementary School - comprising a twenty-year period with intense curriculum reforms, in the context before and after the apartheid. While bearing the specificities of her country in mind, her considerations locate the aforementioned reforms in the wider context of developing countries - thereby becoming especially relevant to the debates about school curriculum in Brazil.

\section{Keywords}

Curriculum reforms - Teaching practices - School education.

\section{Introdução}

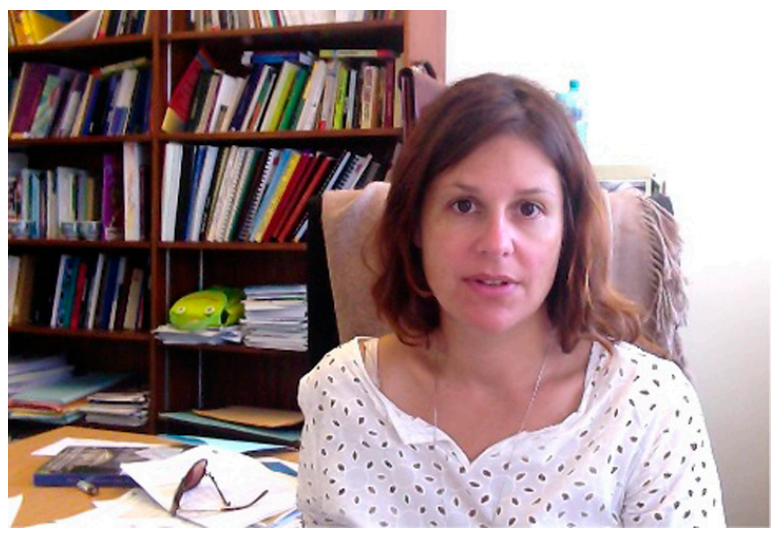

Fonte: arquivo pessoal da autora.
No começo da década de 1970, a Nova Sociologia da Educação (NSE), no contexto europeu, assim como o movimento de reconceptualização do currículo nos Estados Unidos, trouxeram para o campo da educação importantes mudanças na forma de discutir o potencial e os limites da escola na geração de transformações nas trajetórias individuais e sociais. Especificamente no que se refere ao currículo, se desde a primeira década do século XX ele era associado quase que exclusivamente a questões de ordem organizacional ou ao "como fazer" para responder às expectativas sociais sobre a escola, os autores ligados aos movimentos antes mencionados, partindo de diferentes concepções e modos de investigação, explicitaram em seus estudos outra inquietação, centrada no que é definido para ser ensinado na escola e por quê. Em síntese, pode-se dizer que suas indagações se sustentavam na clareza que paulatinamente foi se construindo sobre o caráter político das escolhas curriculares.

Entre os autores da NSE encontra-se Basil Bernstein, sociólogo da educação que desenvolveu ao longo de sua trajetória intelectual todo um arcabouço teórico para o estudo da comunicação pedagógica - mais especificamente para descrever e analisar as formas pelas quais as relações de poder e controle vigentes na sociedade são reproduzidas não só pelo conteúdo selecionado para ser ensinado nas escolas - aspecto salientado pela teoria da reprodução cultural -, mas também pela forma de comunicação estabelecida na relação pedagógica.

Sua teoria constitui uma das principais referências para muitos(as) pesquisadores(as) em todo o mundo (MOORE, 2006; MULLER, 2000; YOUNG, 2008; MORAIS; NEVES, 2001; 
MATON, 2006; WHEELAHAN, 2010; entre outros(as) $\left.{ }^{3}\right)$. Nesse grupo encontra-se Ursula Hoadley, que atua na Faculdade de Educação da Universidade da Cidade do Cabo, na África do Sul. Em seu livro, intitulado Pedagogia na pobreza: lições de vinte anos de reformas curriculares na África do Sul, publicado em 2018, articula a teoria de Bernstein a outras perspectivas (DOWLING, 1998; PEDR0, 1981) para descrever e analisar as práticas docentes desenvolvidas por professoras dos anos iniciais da educação básica (primeiro segmento do Ensino Fundamental, no Brasil) diante de vinte anos de reformas curriculares sul-africanas, no contexto anterior e posterior ao apartheid ${ }^{4}$.

Na entrevista concedida à Educação e Pesquisa, ela trata desse cenário das reformas em seu país e de como ele se relaciona a um movimento mais amplo de reformas em países "em desenvolvimento", da potência descritiva e analítica do arcabouço teórico que mobiliza em suas pesquisas e do interessante conceito que, juntamente com Muller, consolidou e denominou de pedagogia zero, com base na análise de seus achados de pesquisa à luz da teoria de Bernstein. Para além de constituir um interessante exemplo da potência dessa teoria para o desenvolvimento de análises de textos curriculares e de práticas docentes, a entrevista instiga a pensar sobre possíveis aproximações entre a realidade educacional sul-africana e a brasileira, guardadas, claro, as especificidades históricas, sociais e políticas dos dois países.

\section{Referências}

COELHO, Franciele B. de 0 . Análise de currículos de ciências à luz da teoria de Bernstein. Ciência e Educação, Bauru, v. 23, n. 3, p. 795-808, jul. 2017. Disponível em: https://www.scielo.br/scielo. php?pid=S1516-73132017000300795\&script=sci_abstract\&tlng=pt. Acesso em: 20 jan. 2021.

GALIAN, Cláudia. V. A. A recontextualização e o nível de exigência conceitual do conhecimento. Educação e Pesquisa, v. 37, n. 4, p. 763-777, dez. 2011. Disponível em: https://www.scielo.br/scielo.php?script=sci_ arttext\&pid=S1517-97022011000400006. Acesso em: 03 fev. 2021.

MAINARDES, Jefferson; STREMEL, Silvana. A teoria de Basil Bernstein e algumas de suas contribuições para as pesquisas sobre políticas educacionais e curriculares. Revista Teias, v. 11, n. 22, p. 31-54, maio/ago. 2010. Disponível em: https://www.e-publicacoes.uerj.br/index.php/revistateias/article/view/24114/17092. Acesso em: 20 jan. 2021.

MARANDINO, Martha. Análise sociológica da didática museal: os sujeitos pedagógicos e a dinâmica de constituição do discurso expositivo. Educação e Pesquisa, v. 41, n. 4, p. 695-711, jul./set. 2015. Disponível em: https://www.scielo.br/pdf/ep/v41n3/1517-9702-ep-41-3-0695.pdf. Acesso em: 03 fev. 2021.

\footnotetext{
3- Também no Brasil encontram-se pesquisadores(as) que têm mobilizado as ideias desse autor: Sampaio (1998), Mainardes e Stremel (2010), Marandino (2015), Coelho (2017), Galian (2011), entre outros/as.

4- Entre as muitas outras produções da autora, destacam-se: Hoadley (2006, 2012), Hoadley e Galant (2019), Muller e Hoadley (2019), Morgan, Hordern e Hoadley (2019).
} 
MATON, Karl. On knowledge structures and knower structures. In: MOORE, Rob; ARNOT, Madeleine; BECK, John; DANIELS, Harry (ed.). Knowledge, power and educational reform: applying the sociology of Basil Bernstein. London: Routledge, 2006. p. 44-59.

MOORE, Rob. Knowledge structures and intellectual fields: Basil Bernstein and the sociology of knowledge. In: MOORE, Rob; ARNOT, Madeleine; BECK, John; DANIELS, Harry (ed.). Knowledge, power and educational reform: applying the sociology of Basil Bernstein. London: Routledge, 2006. p. 28-43.

MORAIS, Ana M.; NEVES, Isabel P. Pedagogic social contexts: studies for a sociology of learning. In: MORAIS, Ana; NEVES, Isable; DAVIES, Brian; DANIELS, Harry (ed.). Towards a sociology of pedagogy: the contribution of Basil Bernstein to research. New York: Peter Lang, 2001. p. 185-222.

MORGAN, John; HORDERN, Jim; HOADLEY, Ursula. On the politics and ambition of the 'turn': unpacking the relations between Future 1 and Future 3. The Curriculum Journal, v. 30, n. 2, p. 105-124, June 2019. Disponível em: https://bera-journals.onlinelibrary.wiley.com/doi/abs/10.1080/09585176.2019.1575254. Acesso em: 03 fev. 2021.

MULLER, Johan. Reclaiming knowledge: social theory, curriculum and education policy. London: Routledge Falmer, 2000.

MULLER, Johan; HOADLEY, Ursula. Curriculum Reform and learner performance: an obstinate paradox in the quest for equality. In: SPAUL, Nic; JANSEN Jonathan (ed.). South African schooling: the enigma of inequality. A study of the present situation and future possibilities. Switzerland: Springer, 2019. p. 109-126.

SAMPAIO, Mercês M. F. Um gosto amargo de escola: relações entre currículo, ensino e fracasso escolar. São Paulo: EDUC, 1998.

WHEELAHAN, Leesa. Why knowledge matters in curriculum: a social realist argument. London: New York: Routledge, 2010.

YOUNG, Michael F. D. Bringing knowledge back in: from social constructivism to social realism in the sociology of education. London: Routledge, 2008. 


\section{Entrevista}

1. Em 2018 você publicou Pedagogy in poverty: lessons from twenty years of curriculum reform in South Africa. Nesse livro, trata da pedagogia ${ }^{5}$ nas escolas sul-africanas no período de transição entre o regime do apartheid $^{6}$ e 0 democrático, tendo como objeto as reformas curriculares então desenvolvidas e seus possíveis impactos sobre as práticas docentes. Em linhas gerais, o que mudou nos documentos curriculares sulafricanos nesse período e como essas mudanças se relacionam com a transformação do cenário político?

0 currículo no período do apartheid era conteudista, "tradicional”, e carregava uma bagagem ideológica própria de um sistema opressivo e racista. Então, o primeiro currículo pós-apartheid ${ }^{7}$ foi uma ruptura radical com isso - na direção de um currículo baseado em resultados, que estabelecia aprendizagens de forma mais geral e genérica, com a proposição de um regime pedagógico radicalmente construtivista. As disciplinas escolares foram substituídas por áreas transdisciplinares e conteúdos foram largamente removidos.

O sistema educacional, e os professores em particular, estavam totalmente despreparados para as mudanças pretendidas. Notadamente, o estabelecimento de aprendizagens em termos de resultados e competências amplas deixou a maioria dos professores sem orientação sobre o que ensinar, quando e por quanto tempo.

Depois de dois breves anos de implementação, o currículo foi revisado. Ao longo dos 11 anos seguintes, ele foi revisado duas vezes e implicou uma mudança gradual no sentido de conferir centralidade ao conhecimento, ou no sentido de um modelo de currículo por resultados, o que levou à publicação do documento Políticas de Currículo e Avaliação (Curriculum and Assessment Policy Statement - CAPS), em $2011^{8}$.

O CAPS representou um retorno a um currículo baseado nas disciplinas escolares, com especificação clara de conteúdos e rígidos controles sobre a sequência e o compassamento ${ }^{9}$ a ser imprimido no desenvolvimento do currículo. Esse movimento foi considerado por alguns segmentos como uma virada neoliberal em direção a um currículo tradicional dadas algumas similaridades estruturais com o currículo vigente durante o apartheid. Sob a influência do CAPS houve alguma melhora gradual dos resultados dos estudantes, embora em níveis muito baixos.

\footnotetext{
5- 0 termo "pedagogia", em inglês, encontra equivalência com o termo "didática", em português. Remete às escolhas relacionadas à forma de abordar os conhecimentos no processo de ensino. É nesse sentido que está sendo adotado na entrevista.

6 - Segundo o portal GELEDÉS - Instituto da Mulher Negra, o apartheid "foi uma política de segregação social ocorrida na África do Sul entre 1948 e 1994, com a ascensão do Partido Nacional, cujo governo foi composto por uma minoria branca. 0 país foi governado por esta minoria que adotou desde 1948 uma política de segregação racial". Ver: https://www.geledes.org.br/apartheid/

7 - A primeira reforma curricular pós-apartheid, denominada Curriculum 2005 (C2005), foi implementada entre 1998 e 2002.

8- As duas reformas mencionadas pela entrevistada neste parágrafo são: National Curriculum Statement (NCS), implementada entre 2002 e 2011, e Curriculum and Assessment Policy Statement (CAPS), de 2011.

9- De acordo com Bernstein, sequência e compassamento são características da prática pedagógica, assim como a seleção e os critérios de avaliação. Referem-se à escolha do que será ensinado (seleção), a ordem de abordagem desses conteúdos (sequência), o tempo previsto para a sua aprendizagem (compassamento) e a clareza em relação ao que é considerado conteúdo relevante na prática pedagógica (critérios de avaliação).
} 
2. A despeito dessas mudanças no nível das prescrições curriculares, suas pesquisas vêm sinalizando a permanência de uma pedagogia que, em suas palavras, constitui "uma forma de marcar o tempo, um ritual de memorização". Como entende a força dessa pedagogia que tão intensamente marca a constituição do discurso pedagógico nas escolas, especialmente naquelas que recebem os alunos mais pobres, na África do Sul?

Esta pedagogia - ou, as práticas pedagógicas comuns no contexto de países em desenvolvimento - envolve aprendizagens mecânicas, repetições em coro, e cópias e exercícios de fixação. É também caracterizada por um compassamento excepcionalmente lento, um nível muito baixo de complexidade cognitiva na abordagem do conhecimento, pouco espaço para a avaliação das produções individuais dos estudantes e o uso de práticas de instrução visando a uma série de habilidades e necessidades.

Há diferentes formas de entender a persistência dessa pedagogia na literatura. Alguns pesquisadores a relacionam a práticas culturais, especialmente de cunho religioso e missionário, que têm influenciado a natureza da interação na sala de aula. Por isso, essa pedagogia é descrita como ritualizada ou catequética - do tipo "chamada e resposta". Outros, têm associado esse caráter ritualístico a formas de controle, especialmente voltadas a professores que atuam com turmas numerosas e com recursos mínimos. Ter a turma respondendo em uníssono ao professor asseguraria que todos estão participando da mesma forma e ao mesmo tempo. Uma explicação adicional é que este tipo de resposta coletiva mascara o déficit de conhecimentos, da parte do professor e dos estudantes. A turma e o professor estabeleceriam um contrato implícito, que esconde a lacuna de transmissão e compreensão reais.

Eu diria que há elementos de verdade em todas essas explicações. Certamente a pedagogia tem inflexões culturais, traz as marcas de uma compreensão do processo de aprendizagem ligada à atividade religiosa e à reprodução da Escritura. Mas as considerações que enfatizam o controle e a falta de conhecimentos da parte de professores e estudantes representam argumentos convincentes para explicar por que esta pedagogia tem persistido. Creio, também, que com o tempo ela se tornou ritualizada graças à falta de sentido do que se oferece para o professor diante do contexto particular em que atua, o que não contribui para demovê-lo dessas práticas.

3. No livro, você traça um panorama de reformas curriculares de produção recente em países em desenvolvimento, com o intuito de ressaltar traços comuns nesses movimentos, sem perder de vista o que é específico de cada contexto. 0 que lhe chamou a atenção nesse panorama e como isso contribuiu para a análise dos resultados da pesquisa de que trata no livro?

Considerando a literatura sobre as formas assumidas para o currículo e a pedagogia nos países em desenvolvimento, foi notável a similaridade nos tipos de reformas curriculares que foram desenvolvidas nos diferentes contextos. 0 primeiro aspecto que identifiquei em meu livro é que as reformas ao longo dos anos 1990 e do começo dos anos 2000 focalizaram a promoção de pedagogias centradas nos aprendizes (ou nas crianças/ 
nos estudantes) e os métodos e currículos construtivistas. Foi dada ênfase à relevância e à inclusão do conhecimento e das formas de compreensão locais, e houve o impulso na direção do currículo integrado e de abordagens temáticas. Isso foi fortemente apoiado por organizações não governamentais e financiadores internacionais, incluindo o Banco Mundial e a Unesco.

Os aspectos progressistas dessas reformas permaneceram populares até mais recentemente, especialmente na medida em que frequentemente se articulam com agendas políticas progressistas em países em desenvolvimento: foi assumido (e afirmou-se) que ser politicamente progressista significa ser educacionalmente progressista, e que questionar um destes polos, significaria questionar o outro - por exemplo, as reformas curriculares centradas nos alegados interesses e/ou necessidades dos estudantes têm sido recebidas como mais democráticas; refletir sobre possíveis prejuízos associados a este tipo de reforma vem sendo entendido automaticamente como uma posição politicamente nãoprogressista. Essa é uma ideia difícil de ser demovida em ambientes pós-coloniais. Um número de publicações tem mostrado a não efetividade dessa associação direta, apesar de sua persistente afırmação. A configuração aludida acima - a forma pedagógica que prevalece nesses contextos, caracterizada pela aprendizagem mecânica e pela repetição em coro -, tem permanecido como a forma dominante nesses contextos.

A outra tendência de reforma tem sido em direção a currículos baseados em competências; estes, parecem ter passado por duas etapas (e são reciclados continuamente). A primeira foi a adoção de sistemas baseados em resultados, às vezes vinculados às Estruturas de Qualificação Nacionais ${ }^{10}$. A integração estava no topo da agenda, com o "currículo temático" sendo adotado em vários países. A segunda etapa, mais recente, se concentra em estruturas baseadas em competências e numa ênfase nas habilidades necessárias para o século XXI. Isso envolve um redirecionamento do currículo em termos da especificação genérica de uma gama de habilidades. Essa segunda etapa não demoveu inteiramente o currículo baseado nas disciplinas, mas representa, sim, uma ameaça à prioridade dada ao conhecimento no currículo. 0 que ambas essas formas curriculares baseadas em resultados genéricos fazem é colocar o conhecimento das disciplinas em segundo plano. Elas dependem centralmente da qualidade dos professores - seu conhecimento dos conteúdos, sua facilidade com diferentes métodos de ensino e seu acesso a materiais de ensino apropriados. Quando habilidades genéricas substituem o conhecimento formal, as regras do jogo escolar são ocultadas daqueles professores e aprendizes que mais precisariam acessá-las.

\section{A sua trajetória de pesquisa encontra na teoria de Bernstein sua principal referência teórica. Como esse referencial contribui, com seus elementos teóricos e metodológicos, para o desenvolvimento de seus estudos?}

10- Em inglês National Qualification Frameworks. Na página do South African Qualifications Authority (SAQA), essas estruturas de qualificação são definidas como parte de um sistema nacional de educação e formação profissional. São definidas como uma estratégia em resposta a demandas externas sempre em transformação e reúnem um conjunto de princípios e orientações segundo as quais as conquistas na aprendizagem são registradas de modo a permitir o reconhecimento de habilidades e conhecimentos adquiridos, de modo a encorajar a aprendizagem ao longo da vida. Ver: https://www.saqa.org.za/faq/what-national-qualifications-framework-nqf?language_content_entity=en” $\backslash h$ 
Há uma série de razões pelas quais a teoria de Bernstein me auxilia na abordagem dos tipos de questões em que estou interessada, acerca do currículo e da pedagogia. A primeira é que ela oferece uma teorização precisa e delicada dos processos educacionais, dando acesso a uma "anatomia" da pedagogia e a um amplo entendimento sobre as formas curriculares dominantes. Ela também permite que tais formas sejam conectadas às suas lógicas e implicações sociais. Em outras palavras, quais são as implicações dessas formas dominantes para a reprodução social das desigualdades, e para a sua possível interrupção. Em segundo lugar, é uma das poucas teorias do currículo que colocam o conhecimento e a sua investigação no seu centro. Enquanto grande parte da teoria do currículo se concentra em questões de identidade e representação, a teoria de Bernstein conecta esses aspectos às formas de conhecimento e à sua transmissão.

5. Ao analisar as dinâmicas entre conhecimento, currículo e pedagogia ao longo do tempo, você se utiliza da estimulante imagem dos "horizontes cognitivos" dos professores, afırmando que "provavelmente nenhuma reforma terá sucesso sem uma mudança significativa nos horizontes cognitivos daqueles que ensinam em nossas escolas". Em termos gerais, o que essa imagem envolve? Como esses "horizontes cognitivos" articulam o aprimoramento curricular e a alteração em práticas arraigadas nas escolas?

É uma máxima amplamente aceita na educação dizer que os professores ensinam do jeito que eles foram ensinados [no período em que foram estudantes na educação básica]. Isso tem implicações para a forma como a educação, e a pedagogia especificamente, reproduz desigualdades sociais. Em sistemas altamente estratificados, tal como o da África do Sul (e penso que do Brasil também), os professores começam a ensinar sem acessarem prontamente diferentes formas de abordar a pedagogia, e a sua socialização profissional é geralmente muito fraca para interromper os doze anos de aprendizagem sobre o ato de ensinar que os professores desenvolveram ao longo da sua própria escolarização. A ideia de horizontes cognitivos sugere uma ampliação dos repertórios dos professores, uma espécie de aprendizagem sobre como ensinar em relação ao seu próprio contexto, aos alunos e às demandas pedagógicas particulares que estão para além do que já sabem fazer - e que frequentemente não vem funcionando. É cognitivo porque se refere a entendimentos específicos sobre como os professores dão sentido àquilo que fazem.

6. Para finalizar esta entrevista, gostaríamos que discorresse sobre o conceito de "pedagogia zero". Tratando, no campo empírico, de descrever a comunicação pedagógica, você desenvolveu a categoria de enquadramento zero, para caracterizar uma determinada configuração das relações de controle estabelecidas entre professores e alunos. Entendemos que essa questão se relaciona ao que Bernstein aponta sobre o fato de, em certas condições, o discurso pedagógico ${ }^{11}$ ser reduzido ao discurso regulador,

11- Para o autor, o Discurso Pedagógico resulta da inserção do Discurso Instrucional - composto pelos conhecimentos especializados das disciplinas escolares -, em uma base definida pelo Discurso Regulador - que remete aos comportamentos e atitudes que se espera que os estudantes desenvolvam. Assim, o Discurso Instrucional é uma das dimensões do discurso pedagógico, segundo Bernstein (2000). A outra é o Discurso Regulador. 
esvaziando-se a sua dimensão instrucional. Esta nos parece uma ideia muito potente para as pesquisas sobre práticas docentes em países como o Brasil, o que pode ser um modo instigante de terminar esta nossa conversa.

Eu vou te dar uma resposta longa a esta pergunta. A noção de "pedagogia zero" emergiu de uma pesquisa que conduzi, na qual encontrei uma ausência de critérios de avaliação ${ }^{12}$ no discurso instrucional nas aulas que eu havia observado. Embora todas as características da prática pedagógica fossem evidentes (o discurso regulador), não havia qualquer evidência de critérios de avaliação sendo transmitidos. Sugeri, assim, uma possível codificação zero para o enquadramento das regras de critério de avaliação na sala de aula, na qual a pedagogia não é nem fracamente nem fortemente enquadrada ${ }^{13}$. A questão que eu fiz foi: se num encontro pedagógico não há qualquer evidência de aprendizagem, ou de uma mudança pretendida ou real no aprendiz, então isso é pedagogia?

Hugo e Wedekind ${ }^{14}$ retomaram a discussão, argumentando que a ausência de discurso instrucional na pedagogia se traduz na ausência de pedagogia, ou "pedagogia zero" (termo definido por eles). Eles retomam o termo "zero", por mim atribuído aos critérios de avaliação, generalizando-o à pedagogia como um todo. Eles não tratam da distinção entre discurso instrucional e regulador, aplicando o termo "zero" às relações sociais, normas etc.

Zipin ${ }^{15}$ entra no debate, e a sua preocupação na crítica que faz a Hugo e Wedekind refere-se à forma como eles mobilizam o meu argumento para fazer afirmações generalizantes acerca da pedagogia. Ele está correto ao dizer que minhas afirmações limitam-se aos critérios de avaliação, e eu resisto em fazer generalizações com base em um único caso. Mas Zipin está preocupado principalmente com o privilégio concedido por Hugo e Wedekind, e por mim, ao conhecimento especializado sobre o conhecimento cotidiano na relação pedagógica. Ele identifica o privilégio dado ao conhecimento especializado como sendo uma expressão do "imperialismo euro-cultural”, que suprime o debate sobre de quem é o conhecimento que está sendo representado.

Zipin está falando sobre o discurso regulador. Ele está apontando para a necessidade de que o background social dos alunos seja afirmado, e de que estejamos atentos aos propósitos ético-sociais do ensino. Mas esse enfoque não deveria substituir a necessidade de dar às crianças, especialmente àquelas provenientes de meios sociais desfavorecidos, acesso a conhecimentos escolares formais e especializados. Conhecimento cotidiano e

12- Critério de Avaliação, na teoria de Bernstein, é mais uma das características da prática pedagógica - as demais são seleção, sequência e compassamento, como indicado na nota 1. Refere-se ao quanto fica claro ou não para os estudantes o conteúdo relevante e a forma de comunicação considerada legítima nas aulas.

13- Enquadramento é outro conceito de Bernstein, que remete às relações de controle que se estabelecem na comunicação pedagógica - neste caso, sobre a definição dos critérios de avaliação, ou seja, a definição do que é conteúdo relevante e forma de expressão legítima no contexto de sala de aula. Ele é forte, quando esse controle está explicitamente nas mãos do professor; fraco, quando aparentemente está sob domínio dos estudantes. 14- Ver: HUGO, Wayne; WEDEKIND, Volker. Six failures of the pedagogic imagination. Southern African Review of Education, v. 19, n. 1, p. 139158, 2013 e HUGO, Wayne; WEDEKIND, Volke. Ordering principles and operating principles of pedagogy: a reply to Zipin, Southern African Review of Education, v. 19, n. 1, p. 167-176, 2013.

15- Ver: ZIPIN, Lew. Starting from pedagogical zero in "developing" contexts? Let's re-imagine! A response to Hugo and Wedekin. Southern African Review of Education, v. 19, n. 1, p. 158-166, 2013. 
conhecimento especializado deveriam ser vistos de forma relacional em vez de dicotômica, e, dado o contexto escolar, eu argumentaria que a meta final diz respeito crucialmente ao segundo. 0 debate refere-se centralmente aos princípios de ordenação da pedagogia - no sentido da especialização [dos conhecimentos das disciplinas escolares] ou do aprofundamento dos conhecimentos cotidianos de uma comunidade.

A ênfase nos conhecimentos cotidianos [nas aulas], com a exclusão de conhecimentos especializados, codificados, é algo que tem caracterizado há muito tempo o contexto da África do Sul e de muitos outros países em desenvolvimento, derivando frequentemente de reformas curriculares "centradas no aluno". Na África do Sul, a ausência de critérios de avaliação - ou de clareza sobre o que é relevante em termos de conhecimentos e de forma de comunicação - denota um desmoronamento pedagógico fundamental, cujas raízes estão num sistema falido, no empobrecimento histórico daquilo que a escolarização implica, sob o regime do apartheid, em um corpo docente insuficientemente preparado e numa falta de parâmetros profissionais claros guiando a sua prática.

Não se trata de valorização das culturas acumuladas, das comunidades locais ou outras, mas, sim, de exclusão da iniciação dentro de uma cultura de escolarização que leve à aprendizagem. A questão para mim é como nós pensamos sobre esse discurso regulador em relação ao discurso instrucional, e como trabalhamos para entender o conhecimento cotidiano enquanto provedor de uma via para o conhecimento especializado, em contextos particulares.

\section{Bibliografia da entrevistada}

HOADLEY, Ursula; GALANT, Jaamia. What counts and who belongs? Current debates in decolonizing the curriculum. In: Jansen, Jonathan (ed.). Decolonisation in universities: the politics of knowledge, 2019. p. 100-114

HOADLEY, Ursula. What we know about teaching and learning in South African primary schools? Education as Change, v. 16, n. 2, p. 187-202, 2012. Disponível em: https://www.researchgate.net/ publication/272591106_What_do_we_know_about_teaching_and_learning_in_South_African_ primary_schools. Acesso em: 03 fev. 2021.

HOADLEY, Ursula. Analysing pedagogy: the problem of framing. Journal of Education, v. 40, p. 14-34, 2006. Disponível em: http://joe.ukzn.ac.za/Libraries/No_40_2007/Analysing_pedagogy_the_problem_ of_framing.sflb.ashx. Acesso em: 03 fev. 2021.

HOADLEY, Ursula. Pedagogy in poverty: lessons from twenty years of curriculum reform in South Africa. London: New York: Routledge, 2018.

Entrevistadores:

Cláudia Valentina Assumpção Galian - docente do Departamento de Metodologia do Ensino e Educação Comparada (EDM) da FEUSP. Coordenadora do Grupo de Estudos e Pesquisa Escola, Currículo e Conhecimento (ECCo).

Maurício Braz de Carvalho - doutorando do Programa de Pós-graduação em Educação da FEUSP. Membro do grupo de Estudos e Pesquisa Escola, Currículo e Conhecimento (ECCo). 


\section{ERRATA}

Errata: http://dx.doi.org/10.1590/s1517-9702202147 002002E

$\mathrm{Na}$ entrevista Entre reformas curriculares e práticas pedagógicas: Ursula Hoadley e a "pedagogia na pobreza” - DOI: 10.1590/S1678-4634202147002002 publicada em Educação e Pesquisa, v. 47, p. 01-9, e-location e202147002002, 2021, por favor, corrigir:

No título em inglês, onde se lê:

Between curricula reforms and pedagogical practices: Ursula Hoadley and the "pedagogy in poverty"

Leia-se:

Between curriculum reforms and pedagogical practices: Ursula Hoadley and the "pedagogy in poverty" Nas palavras-chaves em inglês, onde se lê:

Curricula reforms - Teaching practices - School education.

Leia-se:

Curriculum reforms - Teaching practices - School education. 